\title{
CONSUMO E NARRATIVA COMO PRODUÇÃO TÁTICA DO ESPAÇO
}

\author{
Laura Fonseca de Castro ${ }^{1}$
}

DOI: 10.5752/P.2316-1752.2020v27n40p171

\section{Resumo}

Neste artigo exploramos criticamente o Urbanismo Tático como método de produção contemporânea cotidiana do espaço. À vista dessa questão, é feita uma análise do caso de construção autônoma de um parquinho infantil no Icaivera, território da Região Metropolitana de Belo Horizonte negligenciado tanto pelo Estado quanto pelo capital privado, que usou apenas recursos materiais rejeitados. É constatado que a comunicação midiática da ação em jornais de grande circulação e nas redes sociais digitais gerou desdobramentos institucionais contraditórios, ao passo que a estratégia narrativa foi capaz de

\footnotetext{
1. Arquiteta e Urbanista pela Universidade Federal de Minas Gerais (UFMG), mestre e doutoranda pelo Núcleo de Pós-Graduação em Arquitetura e Urbanismo da UFMG (Belo Horizonte-MG, Brasil). Visiting scholar e faculty member da The New School for Social Research, no departamento de Liberal Studies (Nova York-NY, EUA). Integrante do grupo de pesquisa Cosmópolis (CNPq). Este artigo toma por base a investigação qualificada em andamento no doutorado de Laura Fonseca de Castro, no Núcleo de Pós-Graduação em Arquitetura e Urbanismo (NPGAU) da Universidade Federal de Minas Gerais (UFMG), sob orientação de Rita de Cássia Lucena Velloso. E-mail: lauracastroo@gmail.com.
} 
promover autonomia local.

Palavras-chave: Urbanismo tático. Produção do espaço. Mídias digitais. Narrativa. Periferia. 


\section{CONSUMPTION AND NARRATIVE AS TACTICAL PRODUCTION OF SPACE}

\begin{abstract}
We critically explore Tactical Urbanism as a method of contemporary everyday life production of space. We analyse the case of the autonomous construction of a children's playground in Icaivera, a territory in the Metropolitan Region of Belo Horizonte neglected by both the State and private capital, which used only prefabricated rejected materials. The media communication of the event in widely circulated newspapers and on digital social networks generated contradictory institutional developments, but the narrative strategy is capable of promoting local autonomy
\end{abstract}

Keywords: Tactical Urbanism. Production of space. Digital Medias. Narrative. Periphery.

\section{CONSUMOY NARRATIVA COMO PRODUCCIÓN TÁCTICA DE ESPACIO}

\section{Resumen}

Exploramos críticamente el Urbanismo Táctico como un método de producción contemporánea del espacio. Analizamos el caso de la construcción autónoma de un parque infantil en Icaivera, un territorio en la Región Metropolitana de Belo Horizonte descuidado tanto por el Estado como por el capital privado, que usaba solo materiales prefabricados rechazados. La comunicación mediática del evento en periódicos ampliamente difundidos y en redes sociales digitales generó desarrollos institucionales contradictorios, pero la estrategia narrativa es capaz de promover la autonomía local.

Palabras-claves: Urbanismo táctico. Producción de espacio. Medios digitales. Narrativa. Periferia. 


\section{Introdução: 0 consumo criativo como modo de produção}

Este trabalho propõe uma reflexão crítica sobre o Urbanismo Tático como método de produção contemporânea e cotidiana do espaço, a partir da análise de um exemplo de prática socioterritorial de antidisciplina realizado na Região Metropolitana de Belo Horizonte e de seus desdobramentos contraditórios ${ }^{2}$. O título é propositalmente provocador ao apresentar o consumo como modo de produção, pois esses dois termos geralmente são considerados como opostos dentro do binômio moderno pela separação dos momentos de trabalho e de lazer. No entanto, após relacionar as bases teóricas do chamado Urbanismo Neoliberal (HARVEY, 2005) aos modos disciplinares de formação subjetiva dos cidadãos urbanos (FOUCAULT, 1999), dirigimo-nos às possibilidades do Urbanismo Tático como método de produção alternativa ao modelo hegemônico orientado em favor do capital (HOU, 2010; LYDON; GARCIA, 2015; BRENNER, 2016).

O termo "tática" será aqui considerado com fundamento no conceito desenvolvido por Michel De Certeau (1998), porém essa prática será atualizada ao estágio pós-industrial e digital em que a sociedade ocidental se encontra

2. O presente trabalho foi realizado com apoio da Coordenação de Aperfeiçoamento de Pessoal de Nível Superior - Brasil (CAPES) - Código de Financiamento 001. 
na década de 20 do século XXI. Entendemos o consumo de bens pré-fabricados como algo incontornável: não porque o consumo seja inerente à nossa condição capitalista atual, mas porque os objetos consumidos pelas vias táticas já existem, material e tecnologicamente, no mundo. Eles servirão de suporte físico para a atualização narrativa de seus significados, a depender do uso que é feito de sua materialidade, dentro da conjuntura política e mediante as relações sociais e culturais nas quais se inserem. Ou seja, os bens pré-fabricados consumidos, efetivamente usados e reinventados em suas funções diárias, potencialmente colaboram para a reorganização simbólica e para a transformação física do espaço e da vida cotidiana.

De acordo com De Certeau (1998), o consumo, quando praticado de maneira tática, seria capaz de superar e desorganizar as fronteiras que estruturam a oposição binária de produção versus consumo. O autor o chama de "uso criativo" e destaca a esperteza dos mais pobres no aspecto da criação de novos instrumentos a partir daquilo que já se tem. Para ele, a partir do uso cotidiano dos objetos para finalidades diferentes daquelas para as quais eles foram fabricados, o consumo seria, ele mesmo, um modo de produzir novos objetos. Argumentamos que, assim como os objetos, o espaço possui uma materialidade inerente que também poderia ser suporte para invenção de novos usos e narrativas diferentes daquelas previstas nos momentos de projeto e construção do espaço. 
Essa hipótese é reforçada pelo fato de que desde a modernidade industrial e da ascensão do movimento modernista em Arquitetura e Urbanismo, é inegável o uso de elementos pré-fabricados e a incorporação de novas técnicas e tecnologias como parte cotidiana do trabalho de planejar e produzir espaços urbanos.

O problema desta pesquisa se coloca a partir da condição contemporânea neoliberal, que se estabelece por meio das práticas de produção do espaço analisadas pelo interior da periferia. Nos territórios periféricos, os efeitos da industrialização e do acesso às tecnologias se dão de modo diferente daqueles localizados nos centros, espaços historicamente orientados pelos costumes burgueses. Neste artigo, será analisado o caso da ocupação da margem de um ribeirão no bairro Icaivera, na Região Metropolitana de Belo Horizonte. Nesse local o dono de um bar mobilizou a vizinhança na construção de um playground infantil, que ficou conhecido como "Parquinho do Nego". A contradição que deriva da tática espacial é notada após a ampla divulgação digital de sua construção (CARNEIRO, 2017), quando o espaço recebeu atenção midiática e foi apropriado estrategicamente pela prefeitura de Contagem. A disputa urbana pelo uso do espaço foi encerrada quando ele foi transformado em uma academia da cidade (PREFEITURA CONTAGEM, 2018). O Icaivera é uma periferia tanto ao considerarmos sua escala local, pois trata-se de um território localizado entre quatro 
municípios marginais à capital da Região Metropolitana, quanto ao examinarmos a condição de precariedade material dos objetos consumidos e do apelo midiático populista a que as comunidades são submetidas no Sul Global (DADOS; CONNELL, 2012).

A questão que exploramos nesse artigo é a possibilidade de ampliação da capacidade narrativa durante o processo tático de produção do espaço, visto que a comunidade possui acesso à internet, às redes sociais e à aparelhos eletrônicos e tecnológicos disponíveis no mercado ${ }^{3}$. Entendemos, baseado na leitura e análise do texto de Michel De Certeau (1998) aplicado às condições urbanas periféricas na América Latina, que o consumo de bens materiais industrializados pode se dar como um rearranjo simbólico que atualiza os significados com base no uso livre dos espaços e suportes midiáticos. Através do uso criativo dos objetos e estruturas físicas pré-existentes, esses novos arranjos podem se diferenciar radicalmente daqueles pré-estabelecidos para os elementos materiais consumidos. O consumo como tática de criação narrativa representa, assim, um desvio, um modo desobediente, despretensioso e potencialmente revolucionário de produzir cidades a partir de suas margens e a partir dos

3. De acordo com os dados disponibilizados em mapa e em indicadores quantitativos pela Agência Nacional de Telecomunicações (ANATEL, 2020a; ANATEL, 2020b), a localidade Icaivera é atendida pelas operadoras Claro, Tim e Vivo com tecnologias 2G, 3 G e 4G. 
objetos produzidos e consumidos dentro do próprio sistema. O alcance simbólico das ações, as intenções, as contradições, os efeitos e os limites desse caso ampliam as possibilidades da discussão teórica para a prática do urbanismo tático no cotidiano das cidades.

\section{As condições contemporâneas neoliberais para o fazer material}

O neoliberalismo estabelece a teoria que o Estado, através das determinações de seu quadro institucional, deve defender a maximização das liberdades empresariais e individuais tendo como base a garantia dos direitos à propriedade privada, à liberdade individual, ao livre mercado e ao livre comércio como práticas políticas e econômicas (HARVEY, 2005). O Estado executa isso por meio da criação de leis, normas, protocolos e aparatos institucionais que garantam o funcionamento do livre mercado e da circulação do capital privado. O argumento retórico principal para proteger o direito individual à liberdade de ação e expressão é que, a partir das práticas de concorrência, as privatizações seriam capazes de aumentar a eficiência, a produtividade e a qualidade de serviços e produtos a serem consumidos, ao mesmo tempo que esses se tornariam mais baratos e com menos impostos embutidos.

A teoria neoliberal defende que o aumento de produtividade e de lucro individual seria capaz de elevar o padrão 
de vida e eliminar a pobreza de toda a coletividade. Sob essa égide teórica, o pensamento neoliberal no âmbito do Estado aposta na privatização dos bens comuns como maneira de eliminar as barreiras de desenvolvimento econômico e de bem-estar social. Na prática, entretanto, o neoliberalismo manifesta contradições que geram graves consequências nos modos de vida urbanos, principalmente para a população mais pobre. O Estado neoliberal omite a assimetria das relações de poder e seus efeitos no acesso aos serviços e produtos disponibilizados pelo mercado. Ao enfatizar a responsabilidade individual sobre o sucesso e o fracasso pessoal, desenvolve uma postura hostil frente às ações sociais de justiça social e de inclusão da diversidade que se colocam como barreira à acumulação de capital e à propriedade privada (HARVEY, 2005).

Sob a perspectiva dos estudos urbanos, é notável que no regime neoliberal o espaço seja visto como mercadoria a ser vendida e consumida. Tanto em escala local quanto global, percebemos a ascensão de uma forma de planejamento estratégico que busca elevar as vantagens comparativas do território com base em sua eficiência. Os critérios para essa comparação são pautados em padrões mercadológicos de competição por investimentos da iniciativa privada. As estratégias de city marketing vendem a imagem de superioridade de uma cidade e de seus atributos em comparação a outras cidades, estabelecendo 
uma relação entre cultura, política e economia em escala global, que visa o lucro financeiro à frente dos interesses sociais de seus habitantes, em escala local. As instituições de gestão municipal assumem a maior parte dos riscos de investimento a fim de se estabelecer competitivamente em relação às outras cidades, socializando os custos das operações urbanas de suposta ampliação de infraestrutura, enquanto os dividendos são privatizados. Os processos de financeirização das terras urbanas colaboram para a especulação imobiliária e para a segregação socioterritorial dos grupos mais pobres. Como efeito desses processos, tais grupos acabam se concentrando às margens dos centros urbanos, onde o acesso a infraestrutura e serviço é mais escasso. Na periferia há menos demanda pela compra da terra e seus preços são mais baixos (GARCÍA; RIBEIRO, 1996).

Nos casos em que a sociedade civil se articula em manifestações coletivas contra as práticas neoliberais, o Estado se encarrega de velar pelos interesses mercadológicos ao ativar instrumentos de vigilância e policiamento que fazem valer a legislação coercitiva disciplinar que reforça a condição de indivíduos sujeitados à "governamentalidade". A respeito do conceito de governamentalidade, ele é a condução dos indivíduos em uma direção determinada de acordo com os interesses de um complexo conjunto de instituições, procedimentos, protocolos, análises, reflexões, cálculos e táticas que regulam a vida 
e os interesses da população (FOUCAULT, 2008). Os processos disciplinares são responsáveis pela formação social daquilo que Michel Foucault (1999) chama de "corpos dóceis", corpos submissos e sujeitos a relações de poder impostas por termos econômicos de utilidade.

A modalidade enfim: implica numa coerção ininterrupta, constante, que vela sobre os processos da atividade mais que sobre seu resultado e se exerce de acordo com uma codificação que esquadrinha ao máximo o tempo, o espaço, os movimentos. Esses métodos que permitem o controle minucioso das operações do corpo, que realizam a sujeição constante de suas forças e Ihes impõem uma relação de docilidade-utilidade, são o que podemos chamar as 'disciplinas'. (FOUCAULT, 1999, p. 118).

A disciplina é responsável por aumentar a força referente à produtividade do corpo como força de trabalho a ser explorado ao mesmo tempo que ela diminui a força desse mesmo corpo como ser político por meio de dispositivos de controle. O corpo é separado do poder como efeito de um processo contínuo de anulação que se dá através de técnicas de coerção, vigilância e obediência. A disciplina, portanto, produz corpos que se submetem a exploração em processos de dominação que ocorrem a partir da internalização da ordem e do controle normativo do comportamento. O controle disciplinar e a consequente anulação política dos corpos implicam em uma mudança nos modos de ação cotidianos na cidade, no ritmo de produção e de consumo, e se voltam para o rendimento 
racionalizado e eficiente, o que legitima a lógica de exploração do trabalho pelo capital.

Sob uma perspectiva marxista, paralela à foucaultiana, pode-se dizer que a modernidade tem como característica essencial as práticas de controle e poder regidos pela sociedade burguesa. Marx (2004) afirma que a sociedade civilizada se realiza por meio do trabalho, por um processo de metabolismo entre pessoa e natureza que resulta em trabalho útil, exteriorizado e efetivado materialmente, pelo qual o homem se reconhece e é reconhecido pelos outros. Mas se o trabalho produtivo livre é a maneira pela qual uma pessoa se realiza e se reconhece com ser social, então o trabalho estranhado e alienado, que responde à necessidade por dinheiro imposta pelas relações de produção capitalistas, seria o responsável pela introdução de uma lógica desumana de reprodução de vida.

Para Marx (2004), a "alienação" se refere ao movimento em direção à abstração do trabalho, em detrimento de sua materialidade, decorrente da apropriação do trabaIho pela lógica de propriedade privada, salário e dinheiro. Esse argumento é fundamental para a compreensão da hegemonia do valor de troca sobre o valor de uso das coisas no capitalismo e, consequentemente, na abordagem neoliberal do espaço. A alienação cotidiana tem efeito no controle disciplinar dos corpos e ações das pessoas que precisam trabalhar seja o que for para conseguirem pagar 
suas contas. O "estranhamento", por sua vez, é o efeito que se manifesta no trabalhador durante as atividades alienadas de produção. O trabalho estranhado consiste na inexistência de uma relação imediata entre o trabalhador e sua produção. Assim dizendo, o sujeito que produz tem uma relação de estranheza com aquilo que é materialmente produzido por ele mesmo, pois o objeto produzido é de propriedade privada de outra pessoa, do proprietário detentor dos meios de produção, e é fruto da expropriação de sua própria liberdade na vida.

O trabalho estranhado e o estado de alienação dos trabalhadores são fundamentais para a constituição do conceito de propriedade privada na acepção marxista. A propriedade privada é o objeto de desejo por excelência no sistema capitalista. Nada pertence a si, nem o trabalho pertence ao trabalhador e, logo, nem o trabalhador pertence a si mesmo. O trabalho alienado e estranhado, típico do regime capitalista, produz não só mercadorias, mas também o trabalhador como uma mercadoria (MARX, 2004). A exploração da condição de precariedade dos trabalhadores pelos proprietários dos meios de produção do seu trabalho estabelece uma cultura de normalização da heteronomia. Do grego, hetero se refere ao "outro", e nomos se refere às "regras", "normas" e "leis". Desse modo, a heteronomia é o oposto da autonomia, pois é o regime em que se seguem as regras estabelecidas pelo outro, não por si. Notamos que tanto a heteronomia 
quanto a autonomia podem se dar de modo individual ou coletivo, quando as normas são estabelecidas por mais de um indivíduo, dentro de um referencial comunitário.

Marx (2004) aponta que o trabalho se inscreve na esfera da necessidade, ou seja, apesar de a atividade produtiva ser essencial para que a pessoa se reconheça como ser genérico humano, ela também é indispensável para o suprimento de necessidades e para a reprodução da vida material. Nesse sentido, o autor afirma que a liberdade só começa onde termina o trabalho estranhado e alienado e que, por isso, deve-se prezar por condições dignas adequadas ao trabalhador. Mesmo que seu texto tenha sido escrito no século XIX, as premissas das condições de trabalho continuam semelhantes nos dias de hoje, porém com um considerável avanço técnico e tecnológico que será considerado mais adiante, notadamente no aspecto cibernético e digital. Por ora, é importante destacar que já na teoria de Marx se inscrevia a dialética entre produção e consumo, pois, se os seres humanos precisam trabaIhar, produzir e consumir para viver, a crítica deve ser feita sobre os modos de produzir, consumir e sobre seus processos de apropriação, objetivação e subjetivação, não sobre uma simples negação das dimensões de produção e consumo. Trata-se de uma revisão de método que só existe ao incorporar teoria e prática juntas. 


\section{$3 \mathrm{~A}$ antidisciplina é uma questão de autonomia im- portante para a transformação das condições ma- teriais de vida}

Michel De Certeau (1998) parte da prerrogativa que o mercado oferece bens pré-fabricados, isto é, os produtos consumidos pela sociedade. A "invenção do cotidiano", título de seu livro, refere-se a uma sociedade antidisciplinar capaz de inventar novos usos para os produtos, que vão além das maneiras programadas de apropriação dos bens de consumo. A sociedade antidisciplinar se baseia na postura criativa da experiência do consumo, no sentido de se opor à passividade provocada pela alienação. Por se tratar da experiência de consumo, da atividade mesma de consumir, o caráter ativo de apropriação de algo para a criação de uma situação representativa da vontade do indivíduo faz com que se estabeleça um esforço de aproximação e interpretação, contrária a de estranhamento e isolamento.

No sentido da experiência, o consumo ativo e antidisciplinar, responsável por criar novas possibilidades de uso para produtos preexistentes, configura-se como produção. Desse modo, a sociedade antidisciplinar se difere do modelo de ordem disciplinar foucaultiana, em que as regras do sistema se fundamentam na repetição dos gestos e no condicionamento dos modos de vida de acordo com a mentalidade de governo. Hoje, essa mentalidade 
está atrelada ao modo de produção capitalista neoliberal (HARVEY, 2005). Quando De Certeau (1998) argumenta sobre a possibilidade do consumo ser uma forma diferente de produção, ele coloca a ação de consumir não como um simples ato que simboliza uma subordinação ao sistema capitalista, mas, sim, como algo que possibilita subverter esse sistema.

No que se refere a práticas socioterritoriais do espaço produzido e consumido dentro de um programa neoliberal de organização das cidades, este trabalho defende que o consumo não precisa ser necessariamente alienado, mas que seria possível o uso criativo e antidisciplinar do espaço se configurar como uma nova forma de produção desse espaço que amplia as possibilidades de experiência através de formas outras de uso. Trata-se, então, da apropriação dos objetos e do espaço material por intermédio da reapropriação do tempo de trabalho envolvido na experiência de uso criativo.

A terminologia desenvolvida por De Certeau (1998) sobre as estratégias e táticas se revela como uma tentativa de diferenciar as maneiras como as estruturas cotidianas são produzidas e consumidas no espaço urbano. Em resumo, na "estratégia", o espaço não se relaciona com seus usuários no que diz respeito às apropriações espontâneas. Por esse ângulo, a produção estratégica do espaço promove uma indiferença e um afastamento que mantém a iden- 
tidade cultural, territorial e pessoal do indivíduo alheia à estrutura física do local, com a finalidade de facilitar a gestão das relações de poder. A passividade é estimulada em favor do consumo. Ao contrário da estratégia, a "tática" é aberta para que os produtos sejam consumidos de modo criativo, o que eleva as múltiplas possibilidades de uso de acordo com as demandas da ocasião, localizada no tempo e no espaço, vivida com o corpo. Na tática, o consumo manifesta seu caráter inventivo, subvertendo o uso programado pré-determinado, funcional e passivo da mercadoria. Logo, o consumo criativo é tático.

A literatura acadêmica sobre o Urbanismo Tático é ampla, e busca evidenciar a necessidade de atualização dos espaços através do uso (HOU, 2010; LYDON; GARCIA, 2015). O termo "Urbanismo Tático" é uma ferramenta utilizada por pesquisadores, produtores culturais, artistas, arquitetos, planejadores, geógrafos etc., a fim de debater questões acerca da produção coletiva de um determinado espaço. O termo reúne manifestações e representações diversas de táticas vividas e desenvolvidas no cotidiano urbano. As ações táticas, em um movimento dialético com as teorias que são elaboradas e informadas por elas, produzem o espaço urbano pela práxis e representam as lutas das comunidades que o habitam, no intuito de redefinir os limites, significados e organização de sua esfera pública. Os grupos e indivíduos se engajam na contestação e na reconfiguração dos espaços que 
habitam a partir de atos que operam na microescala de seu território. Eles são capazes de promover mudanças na cidade hegemonicamente orientada em favor de interesses do Estado neoliberal. Suas ações não demandam grandes investimentos financeiros nem de infraestrutura e, portanto, são capazes de articular agentes locais em torno do estabelecimento de relações de troca e crítica revolucionária, formulada mediante as práticas concretas e capazes de desestabilizar a orientação estratégica presente nos espaços públicos em prol da possibilidade de novas interações e usos.

A produção desses espaços urbanos se dá por meio da apropriação de espaços de uso comum, reformas, eventos temporários, ações performáticas e criação de lugares de encontro informal organizados predominantemente por comunidades marginalizadas social, cultural e/ou territorialmente. Trata-se do consumo criativo das estruturas espaciais já existentes no lugar, que desafiam a noção convencional, normalizada, disciplinada e codificada de produção do espaço. Contudo, no Urbanismo Tático, a produção do espaço se configura através do engajamento da comunidade local e da mídia na crítica das políticas públicas e das parcerias que estabelece com os setores de capital privado (HOU, 2010; LYDON; GARCIA, 2015). Por essa razão, é importante fazer uma distinção das apropriações e considerar o contexto socioeconômico dos espaços onde o Urbanismo Tático se faz. 
Retomando o conceito de tática apresentado anteriormente, é importante frisar que Michel De Certeau (1998) destaca em sua obra a esperteza do pobre, a astúcia que permite inventar novos modos de empregar os produtos disponibilizados pela ordem econômica dominante. Ele aponta para a possibilidade de uma politização das práticas cotidianas a partir do momento em que o mais fraco tira partido dos recursos do mais forte em seu favor, através de táticas de consumo, desvirtuando seu objetivo programado.

"Sempre é bom lembrar que não se deve tomar os outros como idiotas." Nessa confiança posta na inteligência e na inventividade do mais fraco, na atenção extrema à sua mobilidade tática, no respeito dado ao fraco, sem eira nem beira, móvel por ser assim desarmado diante das estratégias do forte, dono do teatro de operações, se esboça uma concepção política do agir e das relações não igualitárias entre um poder qualquer e seus súditos. (DE CERTEAU, 1998, p. 19-20).

Entretanto, há contradições inerentes ao modo tático de produzir espaços, pois eles não são objetos e são de uso inerentemente coletivo. De acordo com Neil Brenner (2016), algumas características do Urbanismo Tático contribuem para a possibilidade de cooptação pelos códigos capitalistas que coordenam o tecido social urbano. Como foi discutido, a característica fundamental do urbanismo chamado neoliberal é a capitalização de ativos de instituições públicas em conjunto com a coordenação dos territórios urbanos por parte de atores privados que pas- 
sam a orientar a vida cotidiana coletiva sob relações de mercado, em favor da classe dominante. A consequência perversa de tal modelo de urbanismo é a precarização espacial e social dos lugares já periféricos e precários em termos de disponibilidade de bens a serem consumidos e transformados.

Por operar em pequena escala e priorizar o curto prazo, uma vez que se refere ao uso e à invenção de soluções para problemas urgentes, o Urbanismo Tático coloca soluções informais, paliativas e imediatas para problemas urbanos estruturantes de um território tal como a precariedade ou ausência de espaços públicos de lazer que poderiam ser abordados de maneiras mais aprofundada e cuidadosa em programas, planos e projetos públicos de médio e longo prazo. Assim, o discurso do Urbanismo Tático acaba por aliviar as responsabilidades do Estado. Brenner (2016) aponta que além de não colaborar com a ampliação da luta coletiva por justiça social, também reforça as práticas neoliberais, pois legitima e sedimenta os laços entre governo que não se preocupa com questões locais coletivas que se omite quanto à responsabilidade de produção e gestão do espaço. Logo, nota-se a transferência da responsabilidade sobre os impactos urbanos, econômicos e sociais para os cidadãos, que se veem vulneráveis frente às iniciativas privadas estratégicas. Assim, a contradição do Urbanismo Tático reside justamente no seu caráter tático, que diminui a importância das ins- 
tituições públicas ao passo que não propõe uma revolução do marco regulatório que orienta o desenvolvimento urbano. A tática nega a estratégia do Estado, mas não propõe uma revolução do marco regulatório institucional neoliberal.

\section{Análise de um caso cotidiano: vida e morte do parquinho do Nego}

O "Parquinho do Nego" está localizado no Icaivera, um território na divisa dos municípios de Contagem, Betim, Esmeraldas e Ribeirão das Neves, na Região Metropolitana de Belo Horizonte ${ }^{4}$. Formalmente, o bairro Icaivera pertence a Contagem, mas uma pesquisa rápida em sites de busca online evidencia a confusão das fronteiras na vida cotidiana local. Há anúncios de imobiliárias e até mesmo reportagens de jornais que dizem "Icaivera, Betim" e "Icaivera, Esmeraldas". Há três anos, em 2017, José Adair de Oliveira, conhecido como Nego, dono de um bar na rua Copissaba, número 235, em frente a um terreno público localizado na margem de um curso d'água

\footnotetext{
4. Destaca-se no título desse item uma ironia com o nome do famoso livro da jornalista Jane Jacobs (2009), "Morte e vida de grandes cidades", o qual apresenta uma crítica das transformações urbanas estratégicas realizadas em Manhattan pelo poder público em favor de interesses privados na década de 1960. O bairro Icaivera e a região do Village, no centro da cidade de Nova York (EUA), a princípio têm pouco em comum quando considerados apenas os aspectos urbanísticos físicos. Entretanto, no que se refere ao modo neoliberal de planejar e produzir metrópoles, há possíveis aproximações: a midiatização dos resultados das construções para fins políticos e institucionais e também como o uso de veículos jornalísticos para a mobilização comunitária para tratar de questões cotidianas podem ser considerados principais características comuns.
} 
usado como depósito de entulho, decidiu usar os próprios materiais abandonados ali para fazer um espaço de lazer para as crianças do bairro. Por conta própria e com a ajuda de vizinhos, ele construiu brinquedos, mesas e cadeiras a partir desses entulhos fazendo o que ele chamou de "gambiarra", baseado em conhecimentos adquiridos "no Youtube e enciclopédias" (CARNEIRO, 2017). Em outras palavras, ele fez uma improvisação com os recursos materiais e as técnicas que ele tinha disponível na situação a fim de atualizar o uso daquele lugar. Ao alterar criticamente a estrutura física do espaço e abrir a possibilidade para outros usos coletivos, Nego realizou ali um consumo tático no espaço.

Em entrevista a um jornal de grande circulação que disponibilizou a reportagem na internet, Nego afirmou que circulavam pelo parquinho entre cinquenta e cem crianças por semana (CARNEIRO, 2017). É interessante notar que a começar do momento em que ele propôs um novo uso para o espaço, ele trouxe à tona a questão urbana da falta de praças e equipamentos públicos na região, da indiferença do Estado quanto às reclamações vindas dos moradores daquele bairro pobre e da ausência de manutenção e do provimento de pessoal de segurança, que causa medo nos moradores especialmente no período noturno. O jornal Folha de São Paulo deu visibilidade ao assunto, ampliando consideravelmente a escala de pessoas com acesso a essa informação e legitimando a reivindicação 
local em um suporte jornalístico formal. Isso teve efeito, inclusive, dentro do próprio Icaivera, o que não chegou desacompanhado de contradições e dissensos. Os desdobramentos da ação tática de Nego antes e depois da publicação da reportagem serão considerados a seguir.

Primeiramente, ao tomar para si a responsabilidade de produção do espaço com recursos materiais escassos, Nego se colocou em uma posição vulnerável no que se refere ao controle do uso coletivo do espaço público, responsabilidade atribuída aos órgãos do governo justamente para servir de anteparo institucional que supostamente trabalha em favor da justiça social via processos democráticos. Nego fez a limpeza do terreno público e a construção do parquinho com entulhos, mas deve-se dizer que o resultado final tinha qualidade material de acabamento precária e baixo nível de segurança para uso infantil, o que gerou desconfiança na comunidade quanto aos interesses e intenções do comerciante com a ação, localizada bem em frente ao seu bar. Por se tratar de uma construção perene, não se poderia desconsiderar a existência da legislação que rege a ocupação do espaço público. Assim, perante a lei, ao construir na margem do rio e ao ocupar uma faixa de preservação permanente para espaço de uso público sem autorização do órgão competente, Nego, tecnicamente, cometeu uma irregularidade e estaria sujeito a sofrer penalidades legais e punições disciplinares. Por esse motivo e por já ter passado por fis- 
calizações decorrentes de denúncias de alguns vizinhos, parte da comunidade local se engajou no esforço de "legalizar" a nova ocupação do terreno público (CARNEIRO, 2017).

De todo modo, Nego interviu no espaço de maneira autônoma coletiva, com o apoio de parte da vizinhança, para requalificar o terreno negligenciado pelo poder público a fim de ampliar seu uso coletivo local, a princípio, sem demonstrar interesse de tomar para si a posse privada individual. Mesmo que não fosse um consenso entre todos os habitantes do território, é importante discutir a legitimidade da ação que toma para si a responsabilidade de alterar as condições espaciais em um contexto de "periferia da periferia", na qual é possível perceber a negligência e o desinteresse tanto por parte do Estado quanto por parte do capital privado. Nego afirma que quando os pais levam as crianças para brincar acabam comprando produtos no seu bar e, logo, a existência do parquinho aumentou o lucro do seu negócio particular ${ }^{5}$ (CARNEIRO, 2017). Levando adiante a possibilidade da ocupação de terrenos públicos para a construção de parques e praças como situação legitimada por lei, a questão da mercantilização do lugar é importante de ser avaliada. Ainda que em microescala, há uma socialização dos custos (da terra

5. Não se deve ignorar a semelhança urbanística do parquinho do Nego com os parklets (DAVIDSON, 2013). 
urbana, que, paradoxalmente, é pública, mas é tomada como propriedade privada do Estado) e de privatização dos lucros (por parte do bar do Nego, com a extensão das mesas e espaços de publicidade) nessa ação tática. Considerando a postura autônoma da comunidade que atua sobre seu próprio território, coloca-se uma contradição interessante a ser analisada: o Urbanismo Tático, que a princípio se estabelece como alternativa à atuação das instituições públicas, poderia culminar em reforço ao regime neoliberal aos quais ele faz oposição?

Notamos que o Estado tem uma postura autoritária nos centros das cidades, com o controle direto sobre o comportamento da população, e, em contraposição, uma postura omissa nas periferias, na qual negligencia suas responsabilidades de defender a justiça social e limita os recursos destinados à manutenção da qualidade de vida para as populações pobres. No caso do Icaivera, um território periférico local, às margens de Belo Horizonte que, por sua vez, também é um centro urbano periférico quando considerado em escala internacional, pois se localiza no Sul Global, percebemos que, ainda que a ação não tenha sido legitimada a princípio pelos órgãos públicos antes do apelo midiático, o acesso às técnicas e tecnologias de construção e comunicação facilitaram o amplo compartilhamento das experiências pela internet.

Somente a partir da cobertura midiática digital o caso 
adquiriu notoriedade entre os moradores da região que não frequentavam aquela rua e também entre os órgãos públicos locais. A contradição apontada quanto à possibilidade de cooptação comercial da tática por interesses capitalistas evidencia as tensões relacionadas às ações realizadas no espaço público, que se originam de iniciativas privadas. Com isso, seria necessário questionar como ocorre o processo de tomada de decisão e de quem são os interesses que intervêm no espaço. Mas antes disso, a prerrogativa é a de que haveria uma disputa de interesses. Na periferia local da periferia global, muitas vezes, os moradores são os únicos interessados e eles não dispõem dos mesmos recursos e conhecimentos técnicos que as instituições ou empresas possuem.

A história do parquinho do Nego tem um desdobramento institucional nada surpreendente. Após a visibilidade adquirida do caso nas mídias digitais, as contínuas denúncias na prefeitura e uma disputa comercial entre os donos de bares do bairro a respeito do uso daquele espaço público como extensão do espaço privado, a prefeitura de Contagem interviu. Um ano depois da publicação da reportagem na Folha de São Paulo, no mesmo lugar onde Nego havia taticamente construído o parquinho, o chão de terra foi cimentado, parte da vegetação foi retirada e foram instalados mobiliários do programa "Academia da cidade". Nas fotos oficiais publicadas no site da prefeitura de Contagem, o novo espaço não é o protagonista, mas, 
sim, os políticos e moradores envolvidos na transformação estratégica do local. Do total de 13 fotos publicadas pela prefeitura, em 7 há pessoas portando câmeras ou smartphones registrando o evento político (PREFEITURA CONTAGEM, 2018).

Aqui, colocamos outra questão a ser discutida: quais são os limites de atuação do neoliberalismo, tanto aquele agenciado pelo Estado, quanto aquele que opera por entidades privadas, em contextos de precariedade tangível e sensível, em situações periféricas? De acordo com Neil Brenner (2016), algumas características do Urbanismo Tático contribuem para a possibilidade de ser cooptado pelos códigos capitalistas que coordenam o tecido social urbano. Como uma reação a essa condição contemporânea, o Urbanismo Tático se manifesta em intervenções imediatas localizadas em microescala de espaço e tempo e trata de questões consideradas urgentes pela comunidade. As pessoas trabalham na produção do próprio espaço de maneira participativa, dentro de um modelo "faça você mesmo", em oposição ao método totalizador, disciplinar e neoliberal de planejamento urbano típico dos projetos estatistas. Tais métodos estratégicos que corroboram para a produção do espaço em função do capital são impositivos nos centros e negligentes nas periferias.

Ao improvisar e criar soluções para problemas urbanos estruturantes de um território tal como a precariedade 
ou ausência de espaços públicos de lazer, que poderiam ser abordados de maneira tecnicamente mais complexa e cuidadosa em programas, planos e projetos de médio e longo prazo pelas instituições públicas democraticamente organizadas, o discurso do Urbanismo Tático acaba por aliviar as responsabilidades do governo nas periferias. Dessa maneira, além de não colaborar com a ampliação da luta coletiva por justiça social, também reforça as práticas neoliberais, pois legitima e sedimenta os laços entre governo que não se preocupa com questões locais coletivas e que se omite à responsabilidade de produção e gestão de espaços sem visibilidade espetacular. Logo, pode-se notar a transferência da responsabilidade sobre os impactos urbanos, econômicos e sociais para os cidadãos, como indivíduos a serem disciplinados, que se percebem vulneráveis em frente de iniciativas privadas estratégicas. Assim, a contradição do Urbanismo Tático reside justamente no elogio absoluto da tática sobre a estratégia, que diminui a importância das instituições públicas como aparato de justiça social, ao mesmo tempo que não propõe uma revolução do marco regulatório que orienta as práticas socioeconômicas urbanas.

\section{Conclusão: desdobramentos inventivos a partir da periferia, mas não em direção ao centro}

A presente discussão suscita perguntas relativas ao uso do espaço como apropriação de objetos e espaços urba- 
nos existentes como meios de manifestação antidisciplinar no cotidiano. Entendemos o Urbanismo Tático como possibilidade de as comunidades locais experimentarem soluções espaciais autônomas, críticas ao modelo totalizador e burocrático do Estado, porém notamos que esse método de produzir espaços pode reforçar as práticas do urbanismo neoliberal. Podemos concluir que existe uma dimensão narrativa indispensável à tática para que ela funcione como ferramenta de empoderamento autônomo local, e essa narrativa pode fazer uso de diversos suportes midiáticos, tanto materiais quanto digitais.

A questão das experiências táticas lida diretamente com o risco de enquadramento e apaziguamento de seu caráter crítico, uma vez que estão inseridas na lógica neoliberal da cidade contemporânea. No entanto, esse aspecto é inerente aos processos de reivindicação espacial, pois tal apaziguamento é efeito dos processos de estranhamento e alienação da pós-modernidade e da era digital na qual estamos inseridos. Nas metrópoles orientadas pelo capital, o indivíduo está constantemente exposto a mudanças de conjuntura política, ética e estética. Uma possibilidade de combate à acomodação dos movimentos de insurgência de conduta disciplinar poderia se dar através da partilha coletiva dos processos vividos, usando quaisquer canais de comunicação disponíveis, inclusive os digitais. Assim como os jornais de grande circulação, as redes sociais e os aplicativos de mensagens instantâ- 
neas possuem atualmente um potencial de amplo alcance dentro das comunidades locais.

Mais do que comunicar os resultados alcançados e celebrar os agentes envolvidos, a narrativa do processo mobiliza a coletividade em torno de projetos comuns e abre a possibilidade de discussão sobre os desacordos. O dissenso é inescapável quando tratamos de objetos e espaços públicos urbanos, coletivos por excelência e, por essa razão, é importante legitimar maneiras outras de ampliar o acesso às ferramentas de discussão e agenciamento durante os processos de produção do espaço para, com isso, promover autonomia coletiva local. Restringir os esforços comunicativos ao registro dos objetos prontos ou legitimar apenas o engajamento presencial direto dos usuários do espaço seria ignorar as novas possibilidades técnicas e tecnológicas já popularmente difundidas e acessíveis na década de 2020.

O Parquinho do Nego ter passado por transformações estratégicas drásticas após a publicação digital da reportagem, do engajamento comunitário contra a exploração lucrativa individual do parquinho e da intervenção estatal, é sintomático da importância de ampliar o acesso coletivo e democrático dos processos de produção do espaço. Ainda que fisicamente o Icaivera se localize na periferia, ele está inserido na rede global de comunicação cibernética pela internet, o que supera as fronteiras formais 
do território já confusas entre os municípios e o insere em uma condição midiática de relações social. Considerar essa nova condição digital em escala mundial ou, ao menos, maior que sua microescala local, dependendo do alcance das mídias de comunicação de tornar públicas as narrativas e de atribuir significado ao espaço é algo potente, mas não deve ser feito de maneira ingênua.

A comunicação deve ser feita em favor do engajamento dos moradores e usuários envolvidos, como ferramenta de autonomia, de modo a não reduzir a um processo narcisista de mercantilização, como se pôde notar pelas fotos de Nego na reportagem da Folha de São Paulo e também dos políticos no site da Prefeitura de Contagem. Comunicar os objetos feitos, terminados, sem abrir a discussão para o processo de sua produção e possibilidades de engajamento, é alienar os moradores da experiência de morar no próprio bairro, um afastamento da possibilidade de trocar, conversar, concordar e até mesmo de brigar entre si. Produzir imagens e distribui-las usando os meios de comunicação digitais, como as plataformas do site oficial da instituição pública, de jornais de grande circulação ou compartilhamento em redes sociais, somente depois de prontas as construções e não como um convite para engajamento e participação no processo de construi-las, é uma atitude que parte da periferia em direção ao centro, que reivindica visibilidade do outro hierarquicamente superior dentro de uma estrutura de poder existente. 
O movimento de partilha narrativa deve ser um movimento de reconhecimento de si através do trabalho, do reconhecimento de si pelo objeto do seu trabalho, do reconhecimento de si a partir do reconhecimento de seus pares e do reconhecimento de si no meio ambiente em que se vive no cotidiano. Essas quatro formas de reconhecimento são os requisitos que Marx (2004) apresenta em seus Manuscritos Econômico-Filosóficos para que a pessoa se reconheça como ser genérico, ou seja, como ser humano que vive em uma sociedade, pelo trabalho. Dessa forma, a narrativa dos processos de produção do espaço é uma estratégia contra o estranhamento, contra a alienação, contra a passividade, contra o espetáculo, contra a disciplina e as relações de poder binárias e hierárquicas entre centro e periferia, através do engajamento no trabalho de produção tática que, por sua vez, se inicia no consumo de bens pré-fabricados.

O território é a base para a experiência urbana, logo, eleva-se seu "valor de uso", lançando mão dos termos de Marx (2013). As táticas espaciais marcam a produção de territórios autônomos na cidade contemporânea como uma alternativa a lógica de produção formal dos espaços regulada pelo Estado e pelo mercado. Assim, o espaço produzido socialmente pelas comunidades locais se revela como uma contraposição às práticas racionalizadas e homogeneizadas determinadas pela governamentalidade neoliberal. 
As manifestações urbanas transformativas que se organizam por meio de táticas revelam que não apenas o caráter econômico do espaço, correspondente a seu valor de troca, é considerado ao longo da vivência diária da comunidade que o habita . Por se articular por meio de iniciativas locais auto-organizadas em microescala, o Urbanismo Tático pode se configurar como ferramenta de planejamento e desenho urbanos que permite a experimentação de uma proposta, o reconhecimento de suas falhas e a abertura para possibilidade de correção e reestruturação futura. As diversas maneiras de produzir o espaço são operadas a partir da promoção de encontros e de trocas cotidianas que potencializam o acontecimento de fóruns de discussão sobre os lugares, expandindo a noção de comunidade presente no espaço público.

Considerar as múltiplas autonomias territoriais táticas manifestadas através do consumo criativo é afirmar uma produção do espaço que parte de ações que se colocam criticamente contra a ordem de controle disciplinar neoliberal praticada pelo Estado. Sem romantizar a precariedade de recursos materiais, que é a base da nossa crítica de afirmação e de negação das táticas, em condições de consumo criativo, percebemos que, na periferia, o consumo dos bens pré-fabricados é uma necessidade, mas também se constitui plenamente como apropriação inventiva, pelo fato da abordagem espacial estratégica não interessar economicamente a atores externos à comu- 
nidade local. A tática é a principal e, por vezes, a única opção na busca da construção do espaço adequado às demandas cotidianas de pequena escala e, precisamente por isso configura-se como um ponto de falha do urbanismo neoliberal e pode se desenvolver como um modo revolucionário de produção.

\section{Referências}

ANATEL, Agência Nacional de Telecomunicações. Telefonia Móvel - Municípios atendidos. (Publicado em 19 jun. 2018, atualizado em 8 jun. 2020). 2020a. Disponível

em: https://www.anatel.gov.br/setorregulado/component/content/article/115-universalizacao-e-ampliacao-do-acesso/telefonia-movel/423-telefonia-movel-municipios-atendidos. Acesso em: 22 jun. 2020.

ANATEL, Agência Nacional de Telecomunicações. Mapa do Sistema de Segurança das Infraestruturas Críticas (SIEC). 2020b. Disponível em: http://sistemas.anatel.gov. br/siec-servico-movel-web/. Acesso em: 22 jun. 2020.

BRENNER, Neil. Seria o "urbanismo tático" uma alternativa ao urbanismo neoliberal? e-metropolis - Revista eletrônica de estudos urbanos e regionais, n. 27, ano 7 , p. 6-18, dez. 2016. Disponível em: http://emetropolis.net/ system/artigos/arquivo_pdfs/000/000/201/original/eme- 
tropolis27_capa.pdf?1485998522. Acesso em: 3 mar. 2020.

CARNEIRO, João. 'Rei da gambiarra', dono de bar transforma terreno em parquinho. Contagem - MG, 10/07/2017 às 2:00. Folha de São Paulo, Seção Cotidiano. Disponível em: http://m.folha.uol.com.br/cotidiano/2017/07/ 1899761-rei-da-gambiarra-dono-de-bar-transforma-terreno-em-parquinho.shtml?cmpid=compfb. Acesso em: 3 mar. 2020.

DADOS, Nour; CONNELL, Raewyn. The Global South. Contexts, v. 11, n. 1 , p. 12-13, Winter 2012. ISSN 15365042. Disponível em: https://journals.sagepub.com/doi/ pdf/10.1177/1536504212436479. Acesso em: 22 jun. 2020.

DAVIDSON, Mariko Mura. Tactical urbanism, public policy reform, and 'innovation spotting' by government: from Park(ing) Day to San Francisco's parklet program. 2013. 63f. Dissertação (Master em City Planning) - Department of Urban Studies and Planning, Massachusetts Institute of Technology. 2013.

DE CERTEAU, Michel. A invenção do cotidiano - 1: Artes de fazer. Petrópolis: Vozes, 1998.

FOUCAULT, Michel. Vigiar e Punir: Nascimento da prisão. Petrópolis: Vozes, 1999. 
FOUCAULT, Michel. Segurança, Território, População. Curso dado no Collège de France (1977- 1978). (Trad. Eduardo Brandão) São Paulo: Martins Fontes, 2008.

GARCÍA, Fernanda Sánchez; RIBEIRO, Ana Clara Torres. City Marketing: a nova face de gestão da cidade no final de século. In: GARCÍA, Fernanda Sánchez; RIBEIRO, Ana Clara Torres. Cultura e Política: Visões do Passado e Perspectivas Contemporâneas. São Paulo: Hucitec / ANPOCS, 1996, p. 103-125.

HARVEY, David. A brief history of neoliberalism. Nova York: Oxford University Press, 2005.

HOU, Jeffrey. (ed.) Insurgent Public Space. Guerrilla Urbanism and the remaking of the contemporary city. Nova York: Routledge, 2010.

JACOBS, Jane. Morte e vida de grandes cidades. 2.ed. São Paulo: WMF Martins Fontes, 2009.

LYDON, Mike; GARCIA, Anthony. Tactical Urbanism. Short-term action for long-term change. Washington: Island Press, 2015.

MARX, Karl. Manuscritos econômico-filosóficos (Trad. Jesus Ranieri) São Paulo: Boitempo, 2004.

MARX, Karl. O Capital: Crítica da economia política. Livro 
1 - O processo de produção do capital. (Trad. Rubens Enderle) São Paulo: Boitempo, 2013.

PREFEITURA CONTAGEM. Prefeito Alex de Freitas assina ordem de serviço para instalação da Academia da Cidade no bairro Icaivera. 9 jul. 2018. Disponível em: http://www.contagem.mg.gov.br/novoportal/PMC\%20 Galeria/prefeito-alex-de-freitas-assina-ordem-de-servico-para-instalacao-da-academia-da-cidade-no-bairro-icaivera. Acesso em: 2 mar. 2019. 